\title{
Prenatal Disruption of Neocortical Development Alters Prefrontal Cortical Neuron Responses to Dopamine in Adult Rats
}

\author{
Antonieta Lavin ${ }^{1,2,3}$, Holly M Moore ${ }^{1,2,4}$ and Anthony A Grace*,1,2 \\ 'Department of Neuroscience, University of Pittsburgh, Pittsburgh, PA, USA; ${ }^{2}$ Department of Psychiatry and Psychology, University of Pittsburgh, \\ Pittsburgh, PA, USA
}

\begin{abstract}
A growing body of evidence suggests that structural changes in the cortex may disrupt dopaminergic transmission in circuits involving the prefrontal cortex (PFC) and may contribute to the etiology of schizophrenia. In this study, we utilize a rodent model of neonatal disruption of cortical development using prenatal administration of the mitotoxin methylazoxymethanol acetate (MAM). Using intracellular recordings in vivo, we compare the physiology of prefrontal cortical neurons and their responses to topical administration of dopamine (DA) in intact animals and adult rats treated prenatally with MAM. Topical administration of DA hyperpolarized the membrane potential (MP) and decreased the firing rate of neurons recorded in deep layers of the PFC in intact animals. Furthermore, electrical stimulation of the VTA evoked fast onset epsps or long-lasting depolarizations in PFC neurons. In comparison, PFC neurons recorded in MAM-treated animals had significantly faster baseline firing rates. Moreover, topical administration of DA did not affect the MP or firing rate of the neurons in MAM-treated animals. However, MAM-treated animals exhibited an increase in the percentage of neurons responding with long-lasting depolarizations to stimulation of the VTA. The results of this study indicate that PFC neurons in the MAM-treated rats are not responsive to DA administered superficially, while at the same time exhibit greater responsiveness to VTA stimulation. These results are consistent with a rewiring of the corticolimbic system in response to neurodevelopmental insults. Neuropsychopharmacology (2005) 30, |426-1435, advance online publication, I3 April 2005; doi: I0.1038/sj.npp. 1300696
\end{abstract}

Keywords: schizophrenia; dopamine; prefrontal cortex

\section{INTRODUCTION}

Several lines of evidence point to the temporal lobe, prefrontal cortex (PFC), and dopamine (DA) transmission in the limbic basal ganglia-PFC circuit as important players in the etiology of schizophrenia. Anatomical studies have reported reduced volume (Bogerts, 1993; Bogerts et al, 1993; Gigg et al, 1994; Howard et al, 1995; Shenton et al, 1992), reduction of neuronal size (Arnold et al, 1995), decreases in the number of synaptic connections (Selemon et al, 1995), and disruption of cellular organization (Akbarian et al, 1993; Altshuler et al, 1987) in the hippocampi of schizo-

\footnotetext{
*Correspondence: Dr AA Grace, Department of Neuroscience, University of Pittsburgh, 458 Crawford Hall, Pittsburgh, PA I5260, USA, Tel: + | 412 624 4609, Fax: + I 412624 9198,

E-mail: Grace@brain.bns.pitt.edu

${ }^{3}$ Current Address: Department of Physiology and Neuroscience, Medical University of South Carolina, Charleston, SC 29425, USA.

${ }^{4}$ Current Address: Department of Psychiatry, Lieber Center, Columbia University, New York, NY 10032, USA.

Received 20 September 2004; revised 5 January 2005; accepted 10 January 2005

Online publication: 14 January 2005 at http://www.acnp.org/citations/ Npp0 I | 405040436/default.pdf
}

phrenia patients, with less severe changes in organization also reported in the PFC (Akbarian et al, 1993). These cortical alterations are believed to reflect disruptions occurring during brain development (Akbarian et al, 1993; Bogerts, 1993; Bogerts et al, 1993; Weinberger and Lipska, 1995). Studies using functional imaging techniques have shown that these structural changes may translate into disruptions in metabolic activity and DA transmission in circuits involving the PFC and temporal cortex (Andreasen et al, 1995; Breier et al, 1992; Buchsbaum et al, 1996; Holcomb et al, 1996; Katz et al, 1996; Siegel et al, 1993; Tamminga et al, 1992; Weinberger et al, 1992).

It is well-documented that the PFC receives a functionally significant DA innervation (Berger, 1992; Domesick 1988; Thierry et al, 1973) that arises from the VTA and establishes synaptic contact with dendritic spines of cortical pyramidal neurons (Cowan et al, 1994; Goldman-Rakic et al, 1989; Ray and Price, 1992; Van Eden et al, 1987). Moreover, several studies have shown that DA reduces synaptic responses in PFC neurons (Ferron et al, 1984; Jay et al, 1995; Law-Tho et al, 1994, 1995). For example, a decrease in firing rate has been observed during extracellular recordings following local administration of DA (Bunney and Aghajanian, 1976; Gratton et al, 1987; Jay et al, 1995; Sesack and Bunney, 
1989) or apomorphine (Mora et al, 1976), and intracellular recordings in vitro showed an increase in spike threshold (Geijo-Barrientos and Pastore, 1995) following DA administration. Furthermore, it has been shown that iontophoretic application of DA depolarized cortical neurons and decreased their firing rate (Bernardi et al, 1982).

Few theories have attempted to relate how structural changes in the hippocampus, PFC or mediodorsal thalamus (MD) would lead to physiological alterations within the thalamocortical circuit (Gratton et al, 1987; Hunt and Aggleton, 1991) and, moreover, how the altered physiology would interact with DA transmission within this circuit (Fuster, 1990; Goldman-Rakic, 1987; Hunt and Aggleton, 1991; Le Moal and Simon, 1991). We have used a rodent model of neonatal disruption of cortical development for the purpose of examining the physiology of the PFC limbic circuit as it relates to the pathophysiology of schizophrenia. This model consists of the prenatal administration of the mitotoxin methyl azoxymethanol acetate (MAM), which interferes with the division and migration of neurons and, depending on the dose and timing of delivery, can selectively affect specific cortical circuits (Moore et al, 2001; Flagstad et al, 2004; Gourevitch et al, 2004). The aim of this study is to characterize normal interactions within the thalamocortical circuit at the level of the PFC and limbic subcortical structures in intact animals, and to compare this with changes in the limbic structures that occur as a result of disruption of the development of projection cells in the hippocampus and limbic frontal cortex. The results presented here examine the electrophysiological properties and spontaneous spike discharge of PFC cells in control and MAM-treated animals, focusing on the response to local administration of DA and the responses evoked by stimulation of the principle afferents to the PFC: the VTA and MD.

\section{METHODS}

All animals were handled in accordance with the procedures outlined in the Guide for the Care and Use of Laboratory Animals published by the USPHS, and the specific protocols used were approved by the University of Pittsburgh Institutional Animal Care and Use Committee. Most of the methods used have been described previously (Lavin and Grace, 1994).

\section{MAM Model}

The model developed in our laboratory (Moore et al, 2001) and employed by others (Cattabeni et al 1989; Banfi et al, 1984; Flagstad et al, 2004; Gourevitch et al 2004) employs administration of a single dose of the antimitotic MAM $(15 \mathrm{mg} / \mathrm{kg}$ i.p.) to pregnant dams (pregnant Fisher albino rats, Hilltop Labs.) at gestational day (GD) 17, which is the time point and dose that was found to provide a relatively selective disruption in the development of the hippocampus and to a lesser extent limbic neocortex (Moore et al, 2001; Grace et al, 1998; Gourevitch et al, 2004). The offspring are weaned at 21 days of age and housed two rats in each cage with food and water available ad libitum until they reach at least $250 \mathrm{~g}$ of weight. Control pregnant rats were given an injection of saline at the same GD to generate the agematched control offspring.

\section{Electrophysiological Recordings}

Experiments were performed in the adult male offspring of the saline-treated and MAM-treated Fisher pregnant rats. The animals were anesthetized with chloral hydrate ( $400 \mathrm{mg} / \mathrm{kg}$ i.p.) and fixed in a stereotaxic apparatus (Narishige SN-2). Supplemental doses of chloral hydrate were administered i.v. via a cannula implanted in the lateral tail vein. The scalp was exposed and holes were drilled in the skull overlying the PFC (coordinates: $\mathrm{AP}=+3.2 \mathrm{~mm}$; $\mathrm{L}=-0.6 \mathrm{~mm}$ from Bregma; $\mathrm{V}=3.0-4.5 \mathrm{~mm}$ from cortical surface, using a $10^{\circ}$ angle away from the midline), the MD (coordinates: $\mathrm{AP}=-3.4 \mathrm{~mm} ; \mathrm{L}=-0.5 \mathrm{~mm}$ from Bregma; $\mathrm{V}=5.2-5.6 \mathrm{~mm}$ from cortical surface), and the VTA (coordinates: $\mathrm{AP}=-4.9 \mathrm{~mm} ; \mathrm{L}=-0.4 \mathrm{~mm}$ from Bregma; $V=8.0 \mathrm{~mm}$ from cortical surface, according to Paxinos and Watson, 1986). Body temperature was maintained at $37 \pm 0.5^{\circ} \mathrm{C}$ using a thermostatically controlling heating pad. Intracellular recordings were performed using electrodes pulled from $1.0 \mathrm{~mm}$ OD. Omegadot glass tubing (WPI) using a Flaming-Brown P-80/PC electrode puller and filled with either (1) $3 \mathrm{M} \mathrm{K}^{+}$acetate (resistance $=60-120 \mathrm{M} \Omega$ ), or (2) $10 \%$ Lucifer yellow in $0.1 \mathrm{M} \mathrm{LiCl}$ (resistance= 100-250 $\mathrm{M} \Omega$ measured in situ).

All electrophysiological recordings were stored and analyzed on-line using a custom-design program (Neuroscope) and also were digitized using a NeuroData Neurocorder and stored on VHS videocassettes for subsequent off-line analysis. Input resistance, firing pattern, firing frequency, membrane voltage oscillations, and evoked responses from MD and VTA, as well as the effects of DA administration on these parameters were examined for each cell recorded. Electrical stimulation of the MD and VTA was performed using bipolar concentric electrodes (Kopf, model SNE-10). Single pulses (0.3 ms duration, 0.1-1.0 mA) were delivered at $2 \mathrm{~Hz}$. The drugs tested were: DA $(300 \mu \mathrm{M})$, saline or glutamate $(50 \mu \mathrm{M})$. DA, saline, or glutamate were administered via topical applications to the superficial layers of the PFC. Topical administration was performed by using a glass micropipette (tip diameter 20-75 $\mu \mathrm{m}$ ) located in the superficial layers of the cortex (layers I-II) proximal to the recording electrode (average distance between the recording electrode and the glass pipette was $600 \mu \mathrm{M}$ ). The glass pipette was connected to a pressure ejection device (WPI, model: PV820). The ejection period was $20 \mathrm{~ms}$ and the ejection pressure ranged between 2 and 5 psi. In order to avoid oxidation, experiments were preformed in a dark room.

All the data are presented as mean \pm SD when appropriate, Student's $t$-test (two tails) or Fisher exact test were used for statistical comparisons. The level of significance was chosen as $p<0.05$.

\section{RESULTS}

The rats used for this study were littermates and showed similar cortical morphology as rats determined to have behavioral deficits associated with frontal cortical pathology including orofacial dyskinesia and exaggerated responses to psychostimulants (Flagstad et al, 2004). A total of 41 neurons were recorded, 20 neurons in control animals and 21 neurons in MAM-treated animals. All the neurons were 
located in deep layers (layers $\mathrm{V}-\mathrm{VI}$ ) of prelimbic or infralimbic cortices.

\section{Basic Physiological Properties of PFC Neurons in Control Rats}

The 20 neurons recorded in the deep layers of the PFC from control animals ( $n=13$ animals) had an average resting membrane potential (RMP) of $-64.4 \pm 7.9 \mathrm{mV}(n=20)$. Approximately $60 \%$ of the population $(12 / 20)$ exhibited bistability of the membrane potential (MP), consisting of a depolarized phase with an average RMP of $-62.3 \pm 7.7 \mathrm{mV}$ and a hyperpolarized phase with an RMP of $-74.0 \pm 9.0 \mathrm{mV}$. Moreover, the MP of the depolarized or up state was significantly different from the MP recorded during the hyperpolarized or down state $(p<0.001, t=-8.53)$. The PFC neurons exhibited an average spontaneous spike threshold of $-54.3 \pm 2.8 \mathrm{mV}$. The average input resistance was $50.2 \pm 22.1 \mathrm{M} \Omega$ and the neurons displayed an average firing frequency of $3.7 \pm 2.7 \mathrm{~Hz}$. The average rheobase current for evoked spikes was $0.47 \pm 0.22 \mathrm{nA}$. These data are summarized in Table 1 . When electrical stimulation was delivered to the VTA, only $1 / 12$ neurons $(8.3 \%)$ responded with a long duration depolarization of the RMP evoked with an onset latency of $40.3 \mathrm{~ms}$ and $4 / 12(33.3 \%)$ of the neurons responded with evoked epsps with an average onset latency of $6.2 \pm 5.0 \mathrm{~ms}$ (Figure 1). Electrical stimulation of the MD produced antidromic-like responses in $35.7 \%$ of the cells recorded (5/14) with an average onset delay of $2.0 \pm 1.0 \mathrm{~ms}$ (Figure 2). In three other cases, stimulation of the MD evoked epsps with amplitudes of $5.5 \pm 0.3 \mathrm{mV}$ and an average onset latency of $2.6 \pm 1.0 \mathrm{~ms}$.

\section{Effects of Local Application of DA in the Physiological Properties of PFC Neurons Recorded in Control Animals}

The effects of local application of DA were tested in 11 neurons, each one recorded in one rat. Administration of
DA to the pial surface $(300 \mu \mathrm{M}, 50 \mu \mathrm{l})$ produced a significant hyperpolarization of the RMP during the up state (control $=-62.3 \pm 7.7 \mathrm{mV} ; \quad \mathrm{DA}=-68.2 \pm 8.0 \mathrm{mV}, p<0.05$, $t=-2.2$ ), and during the down state (control = $-74.0 \pm 9.0 \mathrm{mV} ; \quad \mathrm{DA}=81.9 \pm 12.7 \mathrm{mV}, \quad p<0.02, \quad t=-3.0$, Table 1$)$. Also, there was a trend $(p<0.06)$ for a change in the overall RMP (control $=-64.4 \pm 7.9 \mathrm{mV} ; \quad \mathrm{DA}=$ $-72.5 \pm 12.0 \mathrm{mV}$, Figure 3). DA administration did not alter the spike threshold or input resistance; however, it did produce a significant increase in the rheobase current (control $=0.47 \pm 0.12 \mathrm{nA} ; \mathrm{DA}=0.76 \pm 0.29 \mathrm{nA}, p<0.04$, $t=-2.2$, Table 1). Administration of DA also produced a significant decrease in the average spontaneous firing rate, from $3.7 \pm 2.7 \mathrm{~Hz}$ during control conditions to $1.4 \pm 1.4 \mathrm{~Hz}$ following DA administration $(p<0.01, t=3.05$, Table 1 , Figure 3). The responses evoked by electrical stimulation of the VTA or MD nuclei were not altered by DA administration.

In order to test the specificity of the DA administration, control experiments $(n=4)$ using saline administration or glutamate administration $(50 \mu \mathrm{M})$ were performed. In the case of saline administration $(n=2)$, none of the variables examined exhibited measurable changes. Glutamate administration $(n=2)$ produced a depolarization of the MP by $8.8 \mathrm{mV}$ in the up state (control $=-70.5 \pm 2.0 \mathrm{mV}$; glutamate $=$ $-61.7 \pm 4.3 \mathrm{mV}$ ) and no significant changes in the down state $($ control $=-80.3 \pm 1.0 \mathrm{mV}$; glutamate $=-82.1 \pm 1.9 \mathrm{mV})$. Moreover, glutamate administration caused an increase in the firing rate $($ control $=2.7 \pm 0.1 \mathrm{~Hz}$, glutamate $=$ $6.4 \pm 0.2 \mathrm{~Hz})$.

\section{Basic Physiological Properties of PFC Neurons in MAM-Treated Rats}

A total of 21 PFC neurons were studied in 11 MAM-treated rats. These cells did not exhibit differences in the average MP, up state MP or down state MP, spike threshold, rheobase current or input resistance when compared with

Table I Basal and Evoked Electrophysiological Characteristics of PFC Cells in Control and MAM-Treated Animals. Effects of Local Administration of DA

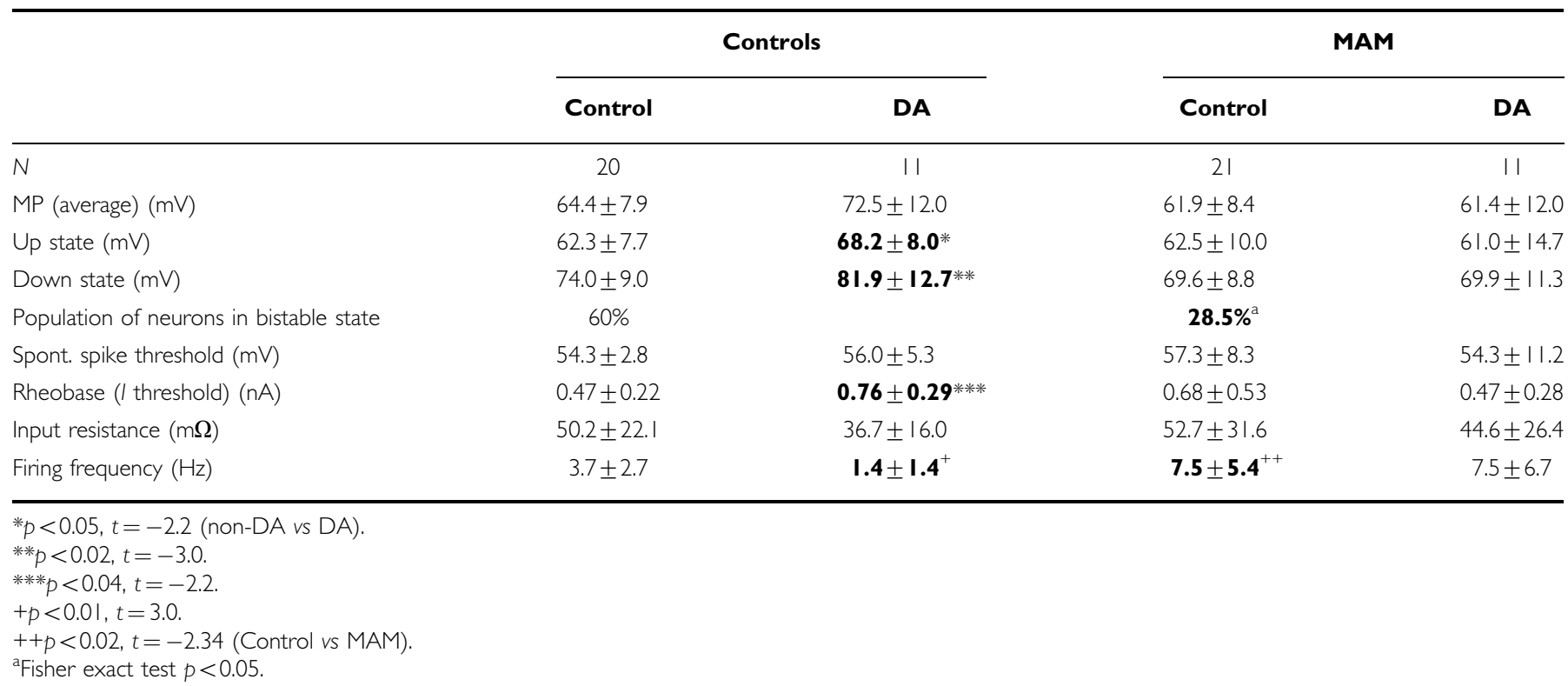

Neuropsychopharmacology 
a
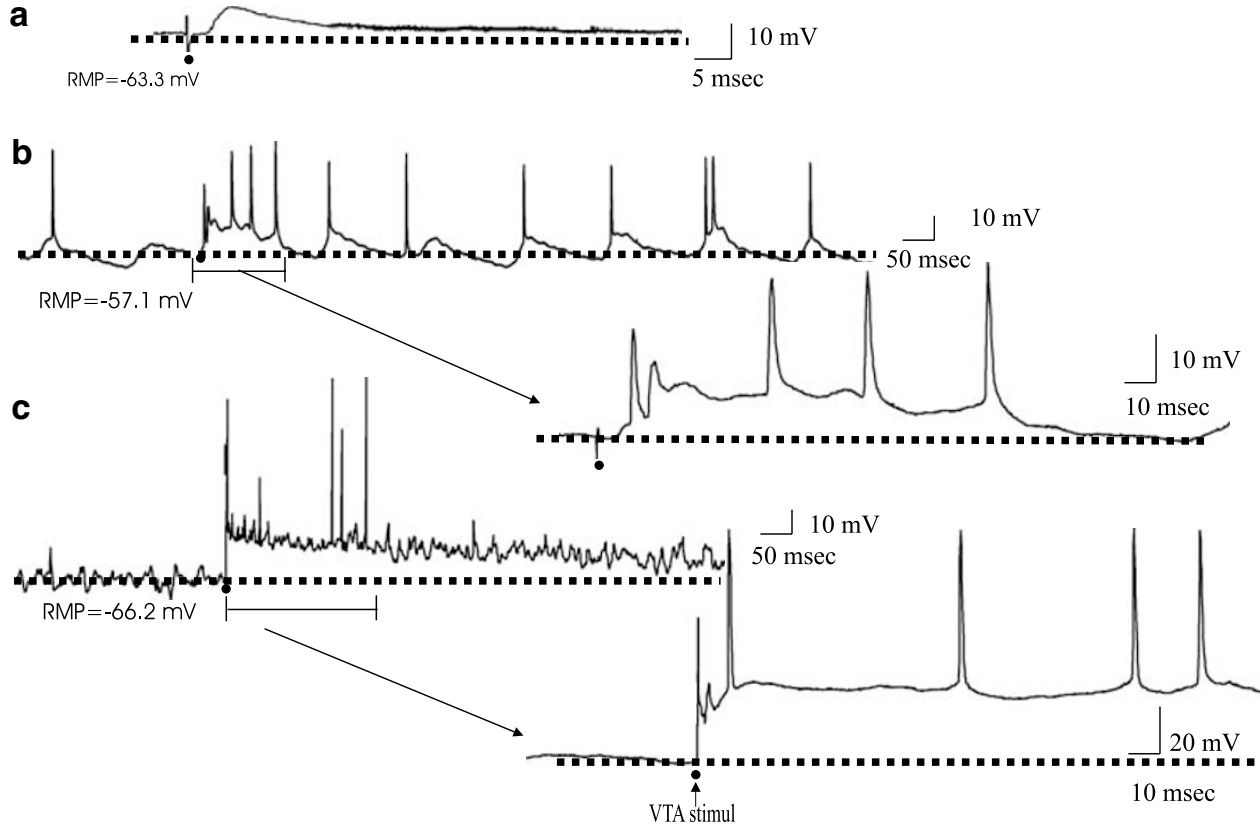

Figure I Electrical stimulation of the VTA evoked short latency EPSPs in PFC pyramidal neurons of control rats but long-lasting depolarizations in the MAM-treated rats. (a) A representative example of the short-latency EPSP evoked by VTA stimulation in control animals. The EPSP has an onset latency of $3.5 \mathrm{~ms}$ and amplitude of $12.5 \mathrm{mV}$. (b) A representative trace of the long-lasting depolarizations evoked by VTA stimulation in the MAM-treated rats. In this neuron, VTA stimulation evoked a depolarization with an onset latency of $8.9 \pm 1.8 \mathrm{~ms}$. The evoked depolarization was longer in duration than the spontaneously occurring depolarizing oscillatory events observed in this neuron. The section of part (b) indicated by parentheses is expanded to show details of the evoked response. (c) In a different PFC neuron, VTA stimulation evoked a very long-lasting depolarization with an onset latency of $5.9 \pm 0.6$ ms and duration of more than $3 \mathrm{~s}$. In this example, the neuron was not firing spontaneously in the baseline state, but exhibited spike discharge during the evoked response. The section of part (c) indicated by the parentheses is expanded to show details of the evoked response. The dotted lines in each figure represent the RMP. The black dots represent the moment that stimulation was delivered to the VTA.

the intact rats (Table 1). In contrast to the control animals, in the MAM-treated rats, just 6/21 (28.5\%) neurons in the PFC exhibited bistability. This represents a decrease of $50 \%$ when compared with the control group. However, the PFC neurons of the MAM-treated rats exhibited significantly faster firing rates compared to control animals (controls $=3.7 \pm 2.7 \mathrm{~Hz}$; MAM-treated animals $7.9 \pm 8.1 \mathrm{~Hz}$, $p<0.02, t=-2.3$, Table 1$)$. In the MAM-treated animals, $3 / 11$ neurons $(27.2 \%)$ responded with antidromic-like activation to stimulation delivered into the $\mathrm{MD}$; the response exhibited an average onset latency of $1.8 \pm 0.7 \mathrm{~ms}$. Furthermore, stimulation of the VTA evoked a long-lasting depolarization in $5 / 11$ neurons $(45.5 \%)$; this represents an increase of $38 \%$ in the number of cells responding to VTA stimulation when compared with the control group. This response exhibited an average onset latency of $5.3 \pm 3.8 \mathrm{~ms}$ (Figure 1). In contrast to the control animals, in the MAM-treated rats, VTA stimulation did not evoke distinct epsps.

Effects of Local Application of DA on the Physiological Properties of PFC Neurons in the MAM-Treated Rats

In contrast to the result found in control animals, in the MAM-treated rats DA administered to the cortical surface did not produce changes in the MP (Table 1), nor did it affect the rheobase current or the firing frequency of the PFC neurons as observed in the control cases. A total of 11 neurons were tested in 11 MAM-treated rats, one cell per animal. As in control animals, DA administration did not affect the evoked responses produced by VTA or MD stimulation.

\section{DISCUSSION}

As stated previously, prenatal MAM treatment resulted in cellular disruption within the hippocampus and temporal cortices. In addition to this disruption of organization, alterations in the morphology of pyramidal cells in the hippocampus and $\mathrm{PFC}$, including a reduction in cell size and in number of dendritic spines, are also produced by MAM treatment (Johnston et al, 1982; Moore et al, 2001) and may be analogous to similar observations made in brains from schizophrenia patients (Arnold et al, 1995; Glantz and Lewis, 1997, 2000; Selemon et al, 1995). The MAM-treated rats also show specific behavioral deficits that show many of the characteristics consistent with an animal model of schizophrenia (Flagstad et al, 2004; Moore et al, 2001). As adults, rats treated prenatally with MAM reliably show cognitive abnormalities, deficits in prepulse inhibition, and hyper-responsiveness to PCP and ketamine (Moore et al, 2001; Mohammed et al, 1986) that are analogous to what has been reported in schizophrenia patients (Braff et al, 1992; Carter et al, 1996; Gray et al, 1995; Itil et al, 1967; Lathi et al, 1994; Malhotra et al, 1996). Moreover, the MAM-treated animals are more responsive to amphetamine administration and to mild stress (Flagstad 


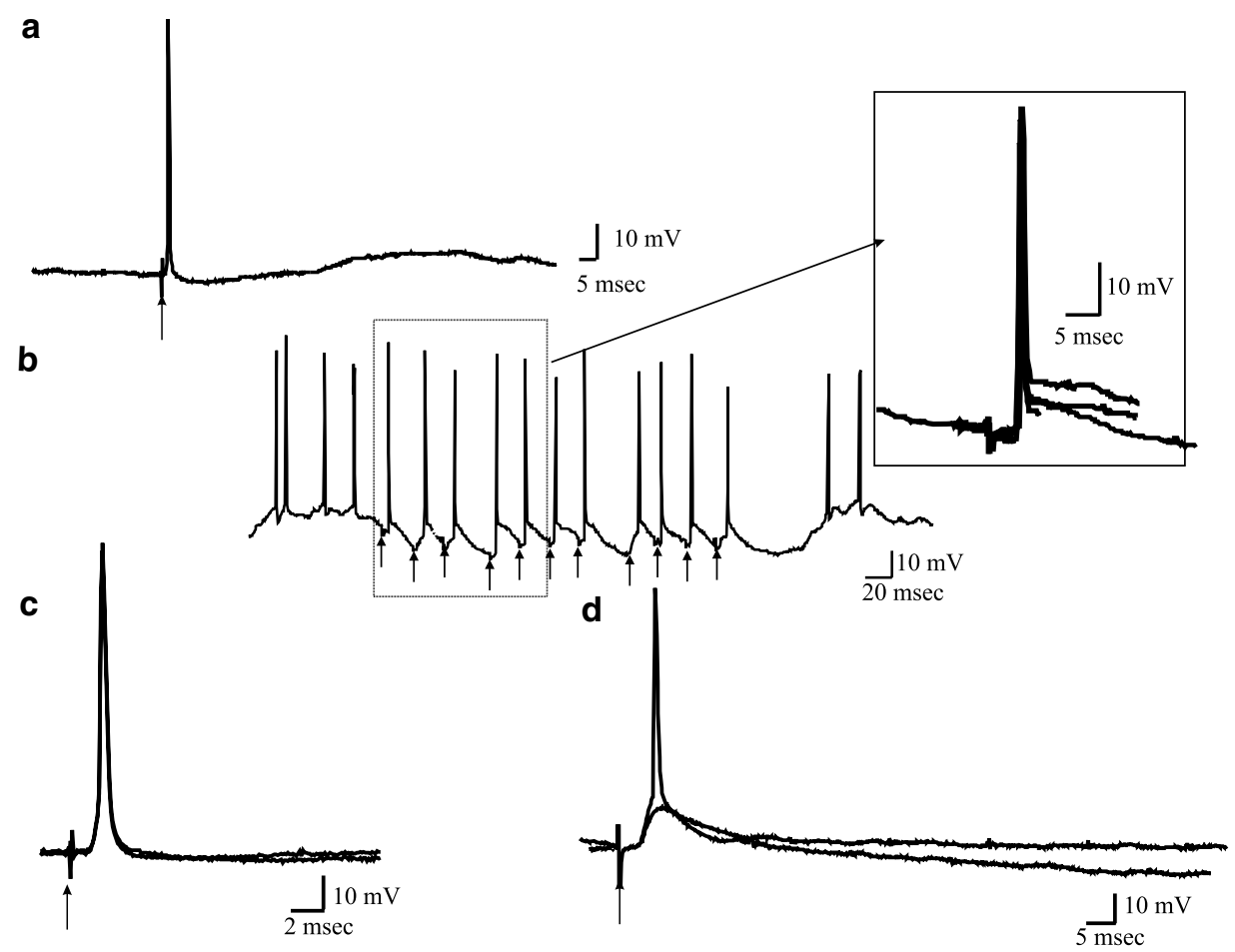

Figure 2 Electrical stimulation delivered to the MD (arrows) evoked excitatory responses in PFC neurons recorded in control and the MAM-treated animals. (a) In $35.7 \%$ of the cases recorded in control animals and $27.2 \%$ of the neurons recorded in the MAM-treated animals, MD stimulation produced antidromic-like responses. This particular neuron exhibited an antidromic-like response with an onset latency of $1.3 \mathrm{~ms}$ and was recorded in the MAMtreated rat. The evoked action potential did not exhibit an underlying epsp. (b) The antidromic-like responses reliably followed frequency stimulations of $50 \mathrm{~Hz}$. The inset illustrates five overlaid consecutive traces shown at a faster time base, in which the action potentials are shown to be triggered at the same latency. (c) A cortical neuron recorded from an intact rat. Two different traces are overlaid depicting antidromic-like spikes following MD stimulation. Note the absence of an underlying epsp. When subthreshold stimulation was delivered no evoked potential was observed. (d) MD stimulation at $300 \mu \mathrm{A}$ also evoked epsps with a latency of $4.2 \mathrm{~ms}$. When the intensity of the electrical stimulation was increased to $450 \mu \mathrm{A}$, an action potential was evoked.

et al, 2004; Gourevitch et al, 2004), results also found in schizophrenia patients (Laruelle et al, 1999; Norman and Malla, 1993).

The PFC neurons recorded in intact rats $v s$ those recorded in the MAM-treated rats exhibited several differences in their physiology. Thus, the PFC neurons recorded in the MAM-treated rats exhibited significantly less bistability in their MP compared to controls. Moreover, the local application of DA to the superficial layers of the PFC in intact animals produced a significant hyperpolarization of the MP, a significant decrease in the firing rate and a significant increase in the rheobase current; however, a similar treatment in the MAM-treated animals did not significantly affect any of these membrane properties. Finally, VTA stimulation evoked long-lasting depolarizations in $45 \%$ of neurons in the MAM-treated rats compared to only $8 \%$ in controls. This was not likely due to differences in the population of neurons recorded, since similar numbers of neurons exhibited antidromic activation from the MD (ie $36 \%$ in controls and $45 \%$ in the MAM-treated rats).

\section{Decrease in Bistability in the MAM-Treated Rat}

One of the more striking findings in this report concerns the decrease in the number of PFC cells exhibiting bistability in the MAM-treated animals, at the same time that the neurons exhibit an increase in firing rate. Bistability has been proposed to play a central role in synchronizing neural networks, thus acting as a kind of filter or gate for information arriving from limbic cortices (Lewis and O'Donnell, 2000). In addition to this interruption of a gating influence, the loss of bistability in the MAM-treated rats would also result in a lack of signal convergence onto postsynaptic targets. Thus, a decrease in bistability could translate to a change in the efficacy of information flow derived from the PFC; that is, in place of a coherent powerful burst of activity, areas receiving PFC afferents would instead be exposed to an irregular, less powerful drive that would likely produce a less potent influence on behavior. It is important to note that loss of bistability does not imply loss of spontaneous firing. In fact, in our study we report that while PFC neurons recorded in the MAM-treated animals exhibited a decrease in bistability, the cells also exhibited an increase in firing rate. Although the origin of the bistable states in PFC has not been elucidated (Cowan and Wilson, 1994; Steriade et al, 1993; Stern et al, 1997), evidence suggest that cortico-cortical interactions may be involved in the regulation of the bistable states in the PFC (Timofeev et al, 2000). Thus, in the MAM-treated animals, the decrease in the number of cells that exhibit these bistable states could indicate that cortico-cortical 
a

b DA

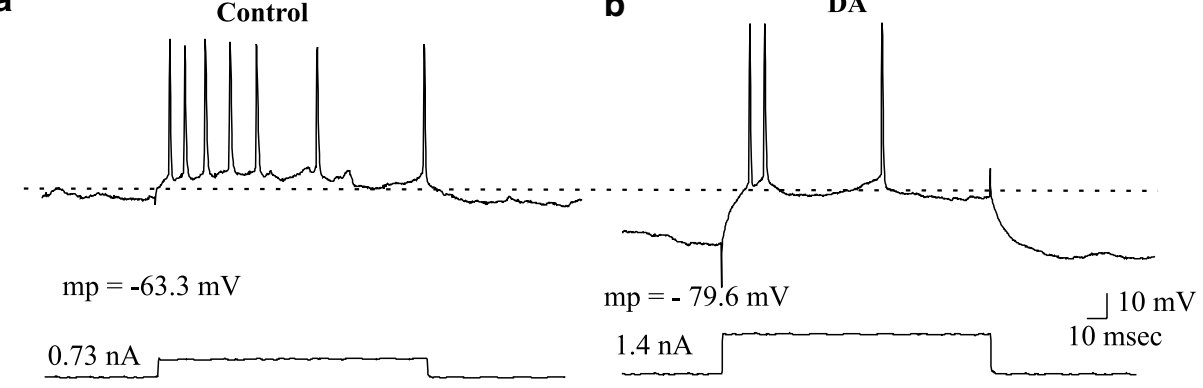

c

MAM Control

d

MAM DA
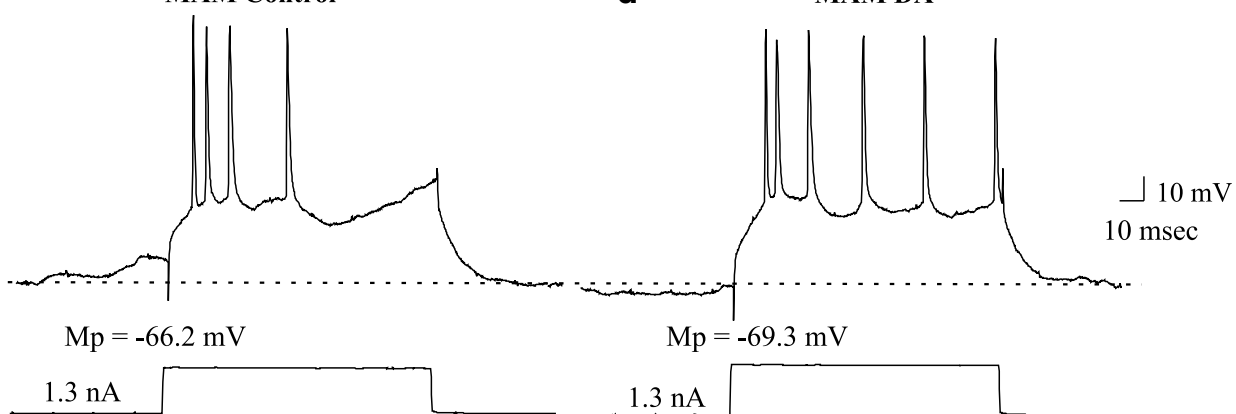

Figure 3 Topical administration of DA to superficial lamina of the PFC hyperpolarized the membrane potential of neurons recorded in deep layers of the PFC in control animals and decreased the firing rate of the cells. (a) Prior to DA administration, this neuron fired seven action potentials in response to a current pulse of $0.73 \mathrm{nA}$; the resting membrane potential of this neuron was $-63.3 \mathrm{mV}$. (b) Following topical administration of DA ( $300 \mu \mathrm{M}$ ), the cell exhibited a hyperpolarization of the membrane potential $(-16.3 \mathrm{mV})$. Under these conditions, injection of nearly double the depolarization current amplitude used in (a) (ie $1.4 \mathrm{nA}$ ) evoked only three spikes. (c) A neuron recorded in the deep layers of the PFC in the MAM-treated rat. This neuron exhibited a resting membrane potential of $-66.2 \mathrm{mV}$ and in response to a depolarizing current injection of $1.3 \mathrm{nA}$ exhibited four action potentials. (d) Following topical administration of DA, the resting membrane potential of the neuron did not change and now the cell responded with six action potentials to the intracellular injection of $1.3 \mathrm{nA}$ depolarizing current.

interactions are altered. Indeed, the loss of DA actions when applied superficially may be particularly significant for the control of cortico-cortical interactions, which typically involve innervation of layers 2-3 (Gonzalez-Burgos et al, 2002).

\section{Effects of Afferent Stimulation}

Our results indicate that cortical neurons in the MAMtreated rats showed an increase in responsivity to VTA stimulation. In control animals, VTA stimulation evoked mainly monosynaptic-like epsps. In contrast, in the MAM-treated animals, VTA stimulation evoked long-lasting depolarizations. Lewis and O'Donnell (2000) have shown that VTA stimulation facilitated transitions to the depolarized or up state in cortical cells. The authors provide evidence indicating that these depolarized or up states were 'maintained 'by the activation of DA D1 receptors. Moreover, in another animal model of schizophrenia involving neonatal lesion of the ventral hippocampus (Lipska et al, 1993 , 1995), VTA stimulation was found to more potently activate neuronal firing in the PFC (O'Donnell et al, 2002). In contrast, we observed a lack of effect of topically applied DA on the discharge of PFC neurons. It is unclear why VTA stimulation would produce a more potent effect in the MAM-treated rats compared to controls, whereas topical
DA would have no effect. One possibility could relate to the differences in DA concentration that are elicited by each method (ie local application at concentrations of $300 \mu \mathrm{M} v \mathrm{~s}$ VTA stimulation, which would achieve high synaptic DA concentrations but comparatively low (ie nM) concentrations extracellularly).

There are other possibilities that could account for the differences between topical administration of DA and VTA stimulation. One may have to do with the site of DA stimulation. Thus, whereas we applied DA to the cortical surface, the VTA exhibits projections that terminate primarily in both superficial as well as deep layers of the PFC (Berger et al, 1991; Descarries et al, 1987; van Eden et al, 1987). If topical DA application is restricted to actions only at superficial layers, our results would suggest that only the DA effects within this region are altered in the MAM-treated rat. Indeed, a model by Yang and co-workers (Yang and Seamans, 1996; Yang et al, 1996, 1999; Seamans and Yang, 2004) suggests that DA may exert differential actions on information processing depending on whether it is increased in the apical $v s$ basilar dendritic regions. Drawing from this model, a loss of superficial DA actions would disrupt the normal modulation of, among other mechanisms, L- and $\mathrm{N}$-type $\mathrm{Ca}^{2+}$ channels resulting in a disruption of signal processing. These authors proposed that such a decrease in DA stimulation could result in a disruption of the normal signal processing, which may 
underlie the heightened distractability and attentional deficits observed in this disorder.

In contrast, it may be that the signal evoked by VTA stimulation that exhibits an enhanced response may not be derived from DA per se. Thus, studies have shown a coexistence of GABA and neurotensin (Hokfelt et al, 1984; Bayer et al, 1991) within this projection system. It is also possible that VTA stimulation would activate fibers of passage. Thus, VTA stimulation has been shown to evoke epsp/ipsp sequences, although these putative monosynaptic events appear to be non-DAergic in nature (Mercuri et al, 1985). The epsps evoked in this study appear to be similar in nature, and may arise from stimulation of fibers of passage, such as those arising from the pedunculopontine nucleus (Jones and Yang, 1985; Satoh and Fibiger, 1986). The role that both the DAergic and non-DAergic afferents may play is not clear at this point; however, it is possible that the loss of DA efficacy could be compensated by an increase in response to these parallel transmitter afferents. Although controversial, another possibility is that the VTA-evoked epsps recorded in the PFC are mediated by glutamate release (Seamans et al, 2002; Chuhma et al, 2004). In this event, our results could suggest that MAM treatment may alter cortical sensitivity to glutamate. It is also possible that both the lack of effects of DA on the MP and the increase in firing rate of the cells recorded from MAM-treated rats could reflect a loss of GABAergic neurons. In fact, in a recent review of post-mortem studies from schizophrenia patients (Coyle, 2004), it was found that a hypofunction of subsets of GABAergic interneurons in the PFC and the hippocampus could underlie some of the deficits related to this disorder. Moreover, Pirot et al (1992) have show that bicuculline administration reverses the decrease in spontaneous firing produced by DA administration, suggesting a role of DA in exciting GABAergic interneurons that will result in a hyperpolarization of pyramidal cells.

Precisely, which mechanism(s) may be present to explain the increase in response to VTA stimulation and the loss of effect of direct DA application will require substantial further research. Nonetheless, the lack of response of PFC neurons to DA administration in the MAM-treated rats is consistent with the proposal of an alteration in the balance of frontal cortical vs subcortical DA actions (Grace, 1991, 1993; Lipska et al, 1993; Flagstad et al, 2004). Moreover, such a condition is functionally analogous to the loss of DA innervation reported in the PFC of schizophrenia patients (Akil et al, 1999; Daniel et al, 1989, 1991). While more studies are needed in order to characterize MAM treatment as a potential animal model of schizophrenia, the results reported in this study indicated that administration of DA to the superficial layers of the PFC in these animals exerts qualitatively different actions than in intact animals and may contribute to the cortical-subcortical imbalance in DA action in developmentally altered systems.

\section{CONCLUSIONS}

The MAM model of neonatal disruption of cortical development appears in many respects to be a potential animal model for the pathophysiology of schizophrenia
(Moore et al, 2001; Flagstad et al, 2004; Gourevitch et al, 2004). Thus, this model in many respects has characteristics that may be analogous to the alterations found in the brains of schizophrenia patients. An emerging model of schizophrenia posits that this disorder is due to a developmental 'rewiring' of corticolimbic systems, possibly as a compensatory response to perinatal hippocampal damage (Lipska et al, 1993; Grace, 1993, 2000). The results of this study showing an increase in PFC neuron firing with a loss of bistability, and an increase in response to VTA afferent stimulation coexistent with a loss of response to topical DA application, is consistent with a model based on a developmental rewiring of the PFC in response to developmental disruptions in the MAM-treated animals.

\section{REFERENCES}

Akbarian S, Vinuela A, Kim JJ, Potkin SG, Bunney WE, Jones EG (1993). Distorted distribution of nicotinamide-adenine dinucleotide phospate-diaphorase neurons in temporal lobe of schizophrenics implies anomalous cortical development. Arch Gen Psychiatry 50: 178-187.

Akil M, Pierri JN, Whitehead RE, Edgar CL, Mohila C, Lewis DA (1999). Lamina-specific alterations in the dopamine innervation of the prefrontal cortex in schizophrenic subjects. $A m J$ Psychiatry 156: 1580-1589.

Altshuler LL, Conrad A, Kovelman JA, Scheibel A (1987). Hippocampal pyramidal cell orientation in schizophrenia. A controlled neurohistologic study of the Yakovlev collection. Arch Gen Psychiatry 44: 1094-1098.

Andreasen NC, Swayze V, O'Leary DS, Nopolus P, Cizadlo T, Harris $G$ et al (1995). Abnormalities in midline attentional circuitry in schizophrenia: evidence from magnetic resonance and positron emission tomography. Eur Neuropsychopharmacol 5(Suppl): 37-41.

Arnold SE, Franz BR, Gur RC, Shapiro RM, Moberg PJ, Trojanowski JQ (1995). Smaller neuron size in schizophrenia in hippocampal subfields that mediate cortical-hippocampal interactions. Am J Psychiatry 15: 738-748.

Banfi S, Dorigotti L, Abbracchio MP, Balduini W, Coen E, Ragusa C et al (1984). Methylazoxymethanol microencephaly in rats: neurochemical characterization and behavioral studies with the nootropic oxiracetam. Pharmacol Res Commun 161: 67-83.

Bayer VE, Towle AC, Pickel VM (1991). Ultrastrctural localization of neurotensin-like immunoreactivity within dense core vesicles in perikarya, but not terminalis, co-localizing tyrosine hydroxilase in the rat ventral tegmental area. J Comp Neurol 311: 176-196.

Berger B, Gasper P, Verney C (1991). Dopaminergic innervation of the cerebral cortex: unexpected differences between rodents and primates. Trends Neurosci 14: 21-27.

Berger B (1992). Dopaminergic innervation of the frontal cerebral cortex. Evolutionary trends and functional implications. $A d v$ Neurol 57: 525-544.

Bernardi G, Cherubini E, Marciani MG, Mercuri N, Stanzione P (1982). Responses of intracellularly recorded cortical neurons to the iontophoretic application of dopamine. Brain Res 245: 262-274.

Bogerts B (1993). Recent advances in the neuropathology of Schizophrenia. Schizophrenia Bull 19: 431-445.

Bogerts B, Lieberman JA, Ashtari M, Bilder RM, Degreef G, Lerner $\mathrm{G}$ et al (1993). Hippocampus-amygdala volumes and psychopathology in chronic schizophrenia. Biol Psychiatry 33: 236-246.

Braff DL, Grillon C, Geyer MA (1992). Gating and habituation of the startle reflex in schizophrenic patients. Arch Gen Psychiatry 49: 206-215. 
Breier A, Buchanan RW, Elkashef A, Munson RC, Kirpatrick B, Gellad F (1992). Brain morphology and schizophrenia. A magnetic resonance imaging study of limbic, prefrontal cortex and caudate structures. Arch Gen Psychiatry 49: 921-926.

Buchsbaum MS, Someya T, Teng CY, Abel L, Chin S, Najafi A et al (1996). PET and MRI of the thalamus in never-medicated patients with schizophrenia. Am J Psychiatry 153: 191-199.

Bunney BS, Aghajanian GK (1976). Dopamine and norepinephrine innervated cells in the rat prefrontal cortex: pharmacological differentiation using microiontophoretic techniques. Life Sci 19: 1783-1792.

Carter C, Robertson L, Nordahl T, Chaderiian M, Kraft L, O’ShoraCelaya L (1996). Spatial working memory deficits and their relationship to negative symptoms in unmedicated schizophrenia patients. Biol Psychiatry 40: 930-932.

Cattabeni F, Abbracchio MP, Cimnino M, Cocchi D, DiLuca M, Mennum Rosi F et al (1989). Methylazoxymethanol-induced microencephalia: persistent increase of cortical somatostaninlike immunoreactivity. Brain Res Dev 47: 156-159.

Chuhma N, Zhang H, Masson J, Zhuang X, Sulzer D, Hen R et al (2004). Dopamine neurons mediate a fast excitatory signal via their glutamatergic synapses. J Neurosci 24: 972-981.

Cowan RL, Sesack SR, Van Bockstaele EJ, Branchereau P, Chan J, Pickel V (1994). Analysis of synaptic inputs and targets of physiologically characterized neurons in rat frontal cortex: combined in vivo intracellular recording and immunolabeling. Synapse 17: 101-111.

Cowan RL, Wilson CJ (1994). Spontaneous firing patterns and axonal projections of single corticostriatal neurons in the rat medial agranular cortex. J Neurophysiol 71: 17-32.

Coyle JT (2004). The GABA-glutamate connection in schizophrenia: which is the proximate cause? Biochem Pharmacol 68: $1507-1514$.

Daniel DG, Weinberger DR, Jones DW, Zigun JR, Coppola R, Handel S et al (1989). The effects of apomoprhine on regional cerebral flow in schizophrenia. J Neuropsychiatry 1: 377-384.

Daniel DG, Weinberger DR, Jones DW, Zigun JR, Coppola R, Handel $S$ et al (1991). The effect of amphetamine on regional cerebral flow during cognitive activation in schizophrenia. J Neurosci 11: 1907-1917.

Descarries L, LeMay B, Doucet G, Berger B (1987). Regional and laminar density of the dopamine innervation in the adult rat cerebral cortex. Neuroscience 21: 807-824.

Domesick VB (1988). In: Kalivas PW, Nemeroff CB (eds). Neuroanatomical Organization of Dopamine Neurons in the Ventral Tegmental Area. New York Academy of Science: New York. p 537.

Flagstad P, Mork A, Glentoj BY, van Beek J, Micahel-Titus A, Didriksen S (2004). Disruption of neurogenesis on gestational day 17 in the rat causes behavioral changes relevant to positive and negative schizophrenia symptoms and alters amphetamineinduced dopamine release in nucleus accumbens. Neuropsychopharmacology 29: 2052-2064.

Ferron A, Thierry AM, Le Dourain C, Glowinski J (1984). Inhibitory influence of the mesocortical dopaminergic system on spontaneous activity or excitatory response induced from the thalamic mediodorsal nucleus in the rat medial prefrontal cortex. Brain Res 302: 257-265.

Fuster JM (1990). Behavioral electrophysiology of the prefrontal cortex of the primate. Prog Brain Res 85: 313-322.

Geijo-Barrientos E, Pastore C (1995). The effects of dopamine on the subthreshold electrophysiological responses of rat prefrontal cortex neurons in vitro. Eur J Neurosci 7: 358-366.

Gigg J, Tan A M, Finch DM (1994). Glutamatergic hippocampal formation projections to prefrontal cortex in the rat are regulated by GABAergic inhibition and show convergence with glutamatergic projections from the limbic thalamus. Hippocampus 4: 189-198.

Glantz LA, Lewis DA (1997). Reduction of synaptophysin immunoreactivity in the prefrontal cortex of subjects with schizophrenia. Regional and diagnostic specificity. Arch Gen Psychiatry 54: 660-669.

Glantz LA, Lewis DA (2000). Decreased dendritic spine density on prefrontal cortical pyramidal neurons in schizophrenia. Arch Gen Psychiatry 57: 65-73.

Goldman-Rakic PS (1987). Circuitry of primate prefrontal cortex and regulation of behavior by representational memory. In: Plum E (ed) Handbook of Physiology. Vol V: Higher Functions of the Brain. American Physiological Society: Bethesda, MD. pp 373-417.

Goldman-Rakic PS, Leranth C, Williams SM, Mons N, Geffard M (1989). Dopamine synaptic complex with pyramidal neurons in primate cerebral cortex. Proc Natl Acad Sci USA 86: 9015-9019.

Gonzalez-Burgos G, Kroner S, Krimer LS, Seamans JK, Urban NN, Henze DA et al (2002). Dopamine modulation of neuronal function in the monkey prefrontal cortex. Physiol Behav 77: 537-543.

Gourevitch R, Rocher C, Le Pen G, Krebs MO, Jay TM (2004). Working memory deficits in adult rats after prenatal disruption of neurogenesis. Behav Pharmacol 15: 287-292.

Grace AA (1991). Phasic versus tonic dopamine release and the modulation of dopamine system responsivity: a hypothesis for the etiology of schizophrenia. Neuroscience 41: 1-24.

Grace AA (1993). Cortical regulation of subcortical dopamine systems and its possible relevance to schizophrenia. J Neural Transm 91: 111-134.

Grace AA (2000). Gating of information flow within the limbic system and the pathophysiology of schizophrenia. Brain Res Rev 31: $330-341$.

Grace AA, Moore H, Lavin A (1998). Disruption of temporal cortical development as an animal model of schizophrenia: alterations in prefrontal cortical-limbic interactions. Int $J$ Neuropsychopharmacol 1(Suppl 1): S24.

Gratton A, Hoffer BJ, Freedman R (1987). Electrophysiological effects of phencyclidine in the medial prefrontal cortex of the rat. Neuropharmacology 26: 1275-1283.

Gray JA, Joseph MH, Hemsley DR, Young AM, Warburton EC, Boulenguez $\mathrm{P}$ et al (1995). The role of mesolimbic dopaminergic and retrohippocampal afferents to the nucleus accumbens in latent inhibition: implications for schizophrenia. Behav Brain Res 71: 19-31.

Hokfelt T, Everitt BJ, Theodorsson-Norhedin E, Goldestein M (1984). Occurrence of neurotensin-like immunoreactivity in subpopulation of hypothalamic, mesencephalic and medullar cathecholamine neurons. J Comp Neurol 222: 543-559.

Holcomb HH, Cascella NG, Thaker GK, Medoff DR, Dannals RF, Tamminga CA (1996). Functional sites of neuroleptic drug action in the human brain: PET/FDG studies with and without haloperidol. Am J Psychiatry 153: 41-49.

Howard R, Mellers J, Petty R (1995). Magnetic resonance imaging volumetric measurements of the superior temporal gyrus, hippocampus, parahipocampal gyrus, frontal and temporal lobes in late paraphrenia. Psychol Med 25: 495-503.

Hunt PR, Aggleton JP (1991). Medial dorsal thalamic lesions and working memory in the rat. Behav Neural Biol 55: 227-246.

Itil T, Keskiner A, Kiremitici N, Holden JMC (1967). Effect of phencyclidine in chronic schizophrenics. Can J Psychiatry 12: 209-212.

Jay TM, Glowinski J, Thierry AM (1995). Inhibition of hippocampo-prefrontal cortex excitatory responses by the mesocortical DA system. Neuroreport 6: 1845-1848.

Johnston MV, Haddad R, Carman-Young A, Coyle JT (1982). Neurotransmitter chemistry of lissencephalic cortex induced in 
ferrets by fetal treatment with methylazoxymethanol acetate. Brain Res 256: 285-291.

Jones BE, Yang TZ (1985). The efferent projections from the reticular formation and the locus coeruleus studied by anterograde and retrograde axonal transport in the rat. J Comp Neurol 242: 56-92.

Katz M, Buchsbaum MS, Siegel Jr BV, Wu J, Haier RJ, Bunney Jr WE (1996). Correlational patterns of cerebral glucose metabolism in never-medicated schizophrenics. Neuropsychobiology 33: $1-11$.

Lathi AC, Koffel B, Laporte D, Tamminga CA (1994). Subanesthetic doses of ketamine stimulate psychosis in schizophrenia. Neuropsychopharmacol 13: 9-19.

Laruelle M, Abi-Dargham A, Gil R, Kegles L, Innis R (1999). Increased dopamine transmission in schizophrenia: relationship to illness phases. Biol Psychiatry 46: 56-72.

Lavin A, Grace AA (1994). The modulation of dorsal thalamic cell activity by the ventral pallidum: its role in the regulation of thalamocortical activity by the basal ganglia. Synapse 18: 104-127.

Law-Tho D, Hirsch JC, Crepel F (1994). Dopamine modulation of synaptic transmission in rat prefrontal cortex: an in vitro electrophysiological study. Neurosci Res 21: 151-160.

Law-Tho D, Desce JM, Crepel F (1995). Dopamine favors the emergence of long-term depression versus long-term potentiation in slices of rat prefrontal cortex. Neurosci Lett 188: $125-128$.

Le Moal M, Simon H (1991). Mesocortical dopaminergic network: functional and regulatory roles. Physiological Rev 71: 155-234.

Lewis BL, O'Donnell P (2000). Ventral tegmental area afferents to the prefrontal cortex maintain membrane potential 'Up' states in pyramidal neurons via D1 dopamine receptors. Cereb Cortex 10: $1168-1175$.

Lipska BK, Chrapusta SJ, Egan MF, Weinberger DR (1995). Neonatal excitotoxic ventral hippocampal damage alters dopamine response to mild repeated stress and to chronic haloperidol. Synapse 20: 125-130.

Lipska BK, Jaskiw GE, Weinberger DR. (1993). Postpuberal emergence of hyper-responsiveness to stress and to amphetamine after neonatal damage: a potential animal model of schizophrenia. Neuropsycopharmacology 9: 67-75.

Malhotra AK, Pinals DA, Weingartner H, Sirocco K, Missar CD, Pickar D et al (1996). NMDA receptor function and human cognition: the effects of ketamine in healthy volunteers. Neuropsychopharmacology 14: 301-307.

Mercuri N, Calabresi P, Stanzione P, Bernardi G (1985). Electrical stimulation of mesencephalic cell groups (A9-A10) produces monosynaptic excitatory potentials in rat frontal cortex. Brain Res 338: 192-195.

Mohammed AK, Jonsson G, Sundstrom E, Minor BG, Soderberg U, Archer T (1986). Selective attention and place navigation in rats treated prenatally with methylazoxymethanol. Brain Res 395: 145-155.

Moore H, Ghajarnia M, Geyer M, Jentsch JD, Grace AA (2001). Selective disruption of prefrontal and limbic corticostriatal circuits by prenatal exposure to the DNA methylation agent methylazoxymethanol acetate (MAM): anatomical, neurophysiological and behavioral studies. Schizophrenia Res 49(S1-2): $2-48$.

Mora F, Sweeney KF, Rolls ET, Sanguinetti AM (1976). Spontaneous firing rate of neurons in the prefrontal cortex of the rat: evidence for a dopaminergic inhibition. Brain Res 116: 516-522.

Norman RM, Malla AK (1993). Stressful life events and schizophrenia. I: a review of the research. $B r J$ Psychiatry 162: $161-166$.
O’Donnell P, Lewis BL, Weinberger DR, Lipska BK (2002). Neonatal hippocampal damage alters electrophysiological properties of prefrontal cortical neurons in adult rats. Cereb Cortex 12: 975-982.

Paxinos G, Watson C (1986). The Rat Brain in Stereotaxic Coordinates. Academic Press: San Diego. pp 1-83.

Pirot S, Godbout R, Mantz J, Tassin JP, Glowinski J, Thierry AM (1992). Inhibitory effects of ventral tegmental area stimulation on the activity of prefrontal cortical neurons: evidence for the involvement of both dopaminergic and GABAergic components. Neuroscience 49: 857-865.

Ray JP, Price JL (1992). The organization of the thalamocortical connections of the mediodorsal thalamic nucleus in the rat, related to the ventral forebrain-prefrontal cortex topography. J Comp Neurol 323: 167-197.

Satoh K, Fibiger HC (1986). Cholinergic neurons of the lateral tegmental nucleus: efferent and afferent connections. J Comp Neurol 253: 277-302.

Seamans JK, Nogueira L, Lavin A (2002). Synaptic basis of persistent activity in prefrontal cortex in vivo and in organotypic cultures. Cereb Cortex 13: 1242-1250.

Seamans JK, Yang CR (2004). The principal features and mechanisms of dopamine modulation in the prefrontal cortex. Prog Neurobiol 74: 1-57.

Shenton ME, Kikins R, Jolesz FA, Pollak SD, LeMay M, Wible CG et al (1992). Abnormalities of the left temporal lobe and thought disorder in schizophrenia. A quantitative magnetic resonance imaging study. $N$ Engl J Med 327: 604-612.

Selemon LD, Rajkowska G, Goldman-Rakic P (1995). Abnormally high neuronal density in the schizophrenic cortex. Arch Gen Psychiatry 52: 805-818.

Sesack SR, Bunney BS (1989). Pharmacological characterization of the receptor mediating electrophysiological responses to dopamine in the rat medial prefrontal cortex: a microiontophoretic study. J Pharmacol Exp Ther 248: 1323-1333.

Siegel BV, Buchsbaum MS, Bunney Jr WE, Gottschalk LA, Haier RJ, Lohr JB et al (1993). Cortical-striatal-thalamic circuits and brain glucose metabolic activity in 70 unmedicated male schizophrenic patients. Am J Psychiatry 150: 1325-1336.

Steriade M, Nunez A, Amizca F (1993). A novel ( $<1 \mathrm{~Hz}$ ) oscillation of neocortical neurons in vivo: depolarizing and hyperpolarizing components. J Neurosci 13: 3252-3266.

Stern EA, Kincaid AE, Wilson CJ (1997). Spontaneous subthreshold membrane potential fluctuations and action potential variability of rat corticostriatal and striatal neurons in vivo. J Neurophysiol 77: 1697-1715.

Tamminga CA, Thaker GK, Buchanan R, Kilpatrick B, Aphs LD, Chase TN et al (1992). Limbic system abnormalities identified in schizophrenia using positron emission tomography with fluorodeoxygluxose and neocortical alterations with deficit syndrome. Arch Gen Psychiatry 49: 522-530.

Thierry AM, Blanc M, Sobel A, Stinus L, Glowinski J (1973). Dopaminergic terminals in the rat cortex. Science 182: 499-500.

Timofeev I, Grenier F, Bazhenov M, Sejnowski TJ, Steriade M (2000). Origin of slow cortical oscillations in deafferented cortical slabs. Cereb Cortex 10: 1185-1199.

Yang CR, Seamans JK (1996). Dopamine D1 receptor actions on layer V-VI rat prefrontal cortex neurons in vitro. J Neurosci 16: 1922-1935.

Yang CR, Seamans JS, Gorelova N (1996). Electrophysiological and morphological properties of layer V-VI principal pyramidal cells in rat prefrontal cortex in vitro. J Neurosci 16: 1904-1921.

Yang CR, Seamans JK, Gorelova N (1999). Developing a neuronal model for the pathophysiology of schizophrenia based on the nature of electrophysiological actions of dopamine in the prefrontal cortex. Neuropsychopharmacology 21: 161-194. 
Van Eden CG, Hoonerman EM, Bujis RM, Matthjssen MA, Geffard M, Uylings HB (1987). Immunocytochemical localization of dopamine in the prefrontal cortex of the rat at the light and electron microscopical level. Neuroscience 22: 849-862.

Weinberger DR, Berman KF, Suddath R, Torrey EF (1992). Evidence of a dysfunction of a prefrontal-limbic network in schizophrenia: a magnetic resonance imaging and regional cerebral blood flow study of discordant monozygotic twins. Am J Psychiatry 149: 890-897.

Weinberger DR, Lipska BK (1995). Cortical maldevelopment, antipsychotic drugs, and schizophrenia: a search for common ground. Schizophrenia Res 16: 87-110. 